\title{
OBSERVATIONS AND REFLECTIONS ON EUROPEAN AGRICULTURE IN GUINEA
}

[Translated by permission from the Jowmal dAgrioultwre Tropicale.]

AN article on "Banana-growing in French Guinea," published in the Journal d'Agriculture Tropicale (No. 53) alludes to the experiments carried on by me in that country, and to the manner in which they were cut short. The publication of results obtained by those who have peisonally made the trial-whether their work were successful or the reverse-is certainly the best possible means of helping forward the cause of tropical agriculture; and this must be my excuse for returning once more to the conclusions at which $I$ arrived in French Guinea.

I have described the beginning of my experiments in an article in the Revue des Sciences (May 15, 1905), and shall therefore not recapitulate their details. I would simply wish to insist on a certain number of points which may be of general interest.

It will be remembered how, on my return from a research expedition into the French Sudan, I thought-and in this I was supported by several friends-that there was room in this country for a serious attempt at agriculture under European supervision.

We considered, however, that it might be imprudent to make our first attempt in a region too difficult of access, and $-M$. Ballay having promised us his support and assistance -we decided to direct our efforts to French Guinea, a country which seemed somewhat easier of development.

A certain number of attempts to form plantations had already been made in French Guinea. All of these had 
aimed almost exclusively at the cultivation of cocoa, coffee, and rubber-trees. They had all practically failed, and it certainly seemed as if this were due to the climate, which, while very moist during the rainy season, has too long a period of drought to suit the greater number of the plants mentioned. 1

It seemed to us, so far as we were concerned, the wisest course to devote ourselves in the first instances to crops requiring no complicated methods of culture, so as to settle as speedily as possible two essential points : cost of labour and productiveness of the soil. We chose the castor-oil plant, which grows wild throughout the greater part of Africa, and which, we were assured, could be grown without difficulty in Guinea. Believing that we might safely trust the above opinion, we cleared and planted 100 hectares. It has already been related how we ascertained that the climate of Guinea was far too damp for this plant. We also began to foresee that the greatest difficulty met with by European planters would be the relative infertility of the soil.

Wishing to be certain on this point, I resolved to begin again with another plant which would surely be able to resist damp and which had, in an even higher degree than the castor-oil shrub, the reputation of being easy to grow.

It will be remembered how at that time it was believed that banana-culture could be made profitable by utilising the meal and the fibre, in countries where the tree flourished, but which were too far from European markets to permit the exportation of the fresh fruit. To make this kind of cultivation pay, however, it would be necessary that the trees should grow, so to speak, without care and without cost.

I have elsewhere related how I planted 8,000 suckers of different varieties procured in the country itself. I set them in holes $60 \mathrm{~cm}$. deep and $30 \mathrm{~cm}$. wide, at intervals of 5 metres over an extent of 20 hectares. On another plot of 4 hectares, I planted them $2 \frac{1}{2} \mathrm{~m}$. apart. In the whole of the plot planted at intervals of $5 \mathrm{~m}$., directly my plants had

1 The coffee-tree, however, seems to flourish in the climate of Guines; but owing to Brallian competition, there is little inducement to cultivate it.-Editorial note, F. d'A.T. 
attained a height of one metre, I left them without weeding. They ought to have gained sufficient strength during the rains to hold their own against the tall weeds, but in this I was disappointed. Their growth remained stationary; and the greater number were choked by the invading bush.

The banana-plants in the four-hectare plot, which had been carefully dug over, but not manured except with a small quantity of guano, reached a height of $1 \mathrm{~m} .50 \mathrm{~cm}$. during the rainy season. They never grew beyond this, however, and produced scarcely any fruit.

From this point, I came to the conclusion that the soil of Guinea was not rich enough to allow any hope of extensive plantations yielding a sufficient return to make them worth undertaking. I then devoted myself to the problem of intensive cultivation, which would admit the application of perfected processes, to remedy the defects of the soil and climate.

To this end, I intended again to try banana-growing, but in conjunction with nursery-gardening; all the more as this would enable me to take advantage of the experiments already made at the Jardin d'Essai. Here, however, I must treat the subject in a more general manner, instead of confining myself to the result of my personal experiments. Without recounting in detail the history of the attempts at bananagrowing made at various times in Guinea, we may at least take a hasty survey of the main points.

About 1898 , the first plantation was established at Rotuma, near Konakry, by a Havre firm, MM. Loizeau and Barral. In 1900, they quitted Rotuma, and made a fresh start at Bramaya. The result was a complete failure. It was attempted to explain this, in a general way, by saying that the ground had been injudiciously chosen for the experiment. This may have been true, as regards Rotuma, but cannot apply to Bramaya, where the soil is much the same as that found over the greater part of Guinea. The fact is that both these plantations had been made without using any manure whatever, as it was thought to be unnecessary in new ground.

About the same time, Maxime Cornu sent a specimen of Musa sinensis from the Museum to the Jardin d'Essai at 
Camayenne. This plant was divided by $M$. Teissonnier, and served to form a plantation containing, in 1903, over a thousand trees. In that year, the exceptional yield of six bunches to each plant was obtained, and the fruit sent to Paris was pronounced finer in appearance and better in quality than anything previously put on the market. At the end of the winter season, a cutting planted out already produced a small cluster of fruit, and by the second winter it was in full bearing.

M. Roux, son of the Paymaster of the colony, encouraged by these results, undertook the laying-out of a banana-garden on ground adjoining the Jardin d'Essai. Five hundred cuttings of Musa sinensis were handed over to him, and planted side by side with cuttings from the Canary Islands and of the indigenous dwarf variety of banana known as diminke. At this time he was acting as adjudicator on the bananas and pineapples grown in the Jardin d'Essai, and began exporting these fruits to France. It will be remembered how enthusiastically they were welcomed by those who thought that a solution was thus furnished for the problem of how to render available the resources of French Guinea. It was declared that French Guinea offered a much more favourable soil for the banana than the Canaries, and that the difficulties arising from distance would be amply compensated by the fact that no rent would have to be paid for land, which in those islands amounts to several thousand francs per hectare.

This was apparently the state of the casc; let us now see what the facts really were.

In a note published in the Journal officiel de la Guinée française ${ }^{1}$ on the mode of cultivation which had produced the admirable results above mentioned, M. Teissonnier expressed himself as follows: "It is obvious that the exclusive use of chemical manures is a mistake; for we must not lose sight of the fact that the soil of a banana-plantation ought to contain a considerable quantity of humus-to be supplied either by farm-manure or compost. The latter can be made every year in large quantities, at a small expense. The

$2 \mathrm{May}, 1903$ 
formula for chemical manures fixed on, after two years' experiments, for use in the Jardin d'Essai, is the following :

Azote, 547 per cent.

Potassium, I I 02 per cent.

Phosphoric acid, 10'20 per cent.

Lime, 8. 17 per cent.

"Besides this manure, the plants should receive, twice a year, sufficient compost or farm-manure to supply the mould indispensable for vegetation. We must therefore reckon that banana-growing in the colony costs I fr. 50 annually per plant, for manure. In this way, we can obtain, in the second year of the plantation, perfectly regular clusters with ten or twelve rows of fruit.

"It will be clear from the above, that the cost of manure per hectare-i.e. for about a thousand plants-will be $1500 \mathrm{fr}$. per annum. Banana-growing therefore must be a purely intensive culture; and it would be imprudent to carry it on over large areas."

The result of my own experiments fully confirms that arrived at by $M$. Teissonnier, especially as regards the necessity for using farm-manure; but I must say that the practical conclusions to be drawn seem far less encouraging to me than they do to him.

Stock-breeding in Guinea is a difficult business, on account of the various diseases from which the animals suffer, and the scarcity of pasturage in the dry season. No fodder can be given except grass, as manioc and similar plants are sold by the natives at too high a price to permit of their being used for this purpose; and it would cost far too much to grow them.

The only district where-for the present, at any ratebanana plantations could be undertaken with any reasonable prospect of success, is that traversed by the railway ; and here the only places where pasturage can be found in the dry season are flooded during the rains, so that cattle would have to be kept at a distance from the plantations, which would scarcely be practicable. Besides, if cattle are kept in order to 
produce manure, they would have to be stalled; it would be difficult to feed them under the circumstances, and it is not certain that they would stand the confinement. It might be possible to keep them in the stable only during the time necessary for fattening them; but, up to the present time, no European stock-breeding enterprise has succeeded in Guinea, and it is questionable whether such an undertaking ever can succeed there.

Finally, the preparation of the manure is not an easy matter in these countries. Contrary to the opinion of some of my friends, I think it will sometimes prove difficult to procure good littering. The tall grass of the scrub country is too long in decaying. That which is used for thatching native huts is better suited for the purpose, but it is not everywhere to be found in large quantities. In any case, it is not well to use this manure unless thoroughly decomposed; otherwise it is an excellent means of getting one's fields infested with white ants. It should only be applied when, by previous preparation, it has been reduced to the consistency of earth. White ants, in fact, greedily devour, not only the straw to be found in the dung, but the dung itself; and this perhaps is the reason why the Fulas, who are almost alone among African tribes in manuring their fields, always previously burn the dung. They have no system of collecting it, beyond picking it up in a dry state on the pasture-lands.

However this may be, I arrived, as I have stated, at the conclusion that the only place suitable for growing bananas and pineapples for export was in the neighbourhood of the railway, on account of the speed with which these fruits would have to reach the port of embarkation. Moreover, the brackish water towards the mouth of the rivers was of no use for the copious irrigation absolutely necessary during the dry season. I therefore resolved to begin by starting a nursery at Camayenne, which should supply me with the elements of a new plantation. In this work I employed the early part of 1903. It was, in short, a new undertaking which had to be begun on an entirely new basis.

It will be remembered that $M$. Teissonnier's declarations, and my own, as to the necessity for using large quantities of 
manure in banana-growing, were not well received in France. The idea that the soil in Guinea was not of the most fertile description seemed extraordinary, and the assertion that diffculties might be met with in banana-growing, a mere paradox. It will also be remembered that I stated the question thus :

"It may be considered that banana-growing should, in Guinea, be an intensive culture, directed to small areas which must be made to yield as large a crop as possible. By the application of M. Teissonnier's formula, it seems as if one might be able to obtain a remunerative crop. Will it, however, be possible to apply to a plantation laid out with a view to profit, this formula which has as yet been tried only on a small scale?" I must acknowledge that for my part I did not consider the matter sufficiently proved to advise my friends to risk fresh funds in an enterprise of this kind :the less so, because, as I have explained in the Revue des Sciences, the cultivation of the land bordering on the railway line appeared to me to be decidedly none of the easiest. Independently of the small area of cultivable ground, it is not certain that at all points along the line results can be obtained equal to those recorded at Konakry. The soil is not of the same character, and new experiments with manure would be necessary; the climatic conditions are not the same; the altitude is different; and at a great distance from the sea the fruit produced would perhaps be of inferior quality.

An indisputable fact is that, in the villages of this district, no banana-trees are to be found as vigorous as those growing near the rivers. They are very slight, their leaves are stunted, and the fruit extremely small. This difference must surely have a cause which remains to be ascertained. 1 Lastly, the ravages of locusts are more marked in the interior than on the coast.

In reality, the experimental stage was not yet over, and I was forced to admit that several years' work would still be required before we could-not make a profit, but-know what

\footnotetext{
1 Some authorities find a sofficient explanation in the Harmattan, the burning ast wind which, in the season when it previle, dries up and corrodes all tender reqetable tivues-Editorial Note, J. d'A. T.
} 
was the right course to pursue. We therefore interrupted our operations.

Meanwhile, public enthusiasm in favour of banana-growing in Guinea was steadily increasing. An attempt was made by M. Adrau, who, however, did not persist in it long; then came the expedition of MM. Dybowski and Hollier, and a series of small plantations were soon formed at Camayenne, managed by a certain number of officials, by M. Dubot, and above all by $M$. Vacher, who resigned his position as Agent-General of the Compagnie Francaise de l'Afrique Occidental, in order to devote himself more entirely to his bananagarden.

I considered for my own part that it was not my duty to say anything calculated to fetter this movement. I had confined myself to thinking and declaring that the experimental period was not yet at an end; and where I had stopped short, others might succeed. I believed it advisable, however, to publish the result of my observations, and therefore wrote the article in the Revue des Sciences. I wrote it in as temperate a spirit as possible, being clearly conscious that I had not yet reached any final solution of the problem.

I felt myself so much alone, however, in my opinion as to the difficulties of European agriculture in Guinea, that I kept back my article from publication till May, 1905, being unwilling to contribute to the possible failure of a movement for the agricultural development of Guinea. I was the less desirous of discouraging those who wished to continue the work which I had been among the first to undertake, as those who predicted success for the banana-plantations in French Guinea assured us that it would be immediate : a plantation was to produce a crop at the end of the first year, and yield heavy profits after the second. There were four possible cases:

(I) It was not necessary to use the strong doses of chemical manure recommended by $M$. Teissonnier, and it would therefore be more economical to content one's self with a smaller number of clusters, just enough to pay the minimum of general expenses, by cultivating a large extent of ground. 
(2) Chemical fertilisers might be sufficient, to the exclusion of animal manure.

(3) It might prove less difficult than I had anticipated to obtain animal manure.-In either of these three cases, success might, in fact, be immediate.

(4) Or, lastly, the situation might actually be such as I had contemplated.

Two years and a half have now elapsed since that time. The oldest of the Camayenne plantations, which ought to have been in full bearing two years ago, could not be kept up by its owner; and on the other hand, Vacher died in the midst of his work.1 Consignments of several hundred clusters have from time to time been shipped from Konakry; yet it seems that this trade has not yet reached the stage of a serious practical organisation. The state of things appears to be much as I had suspected.

Moreover, M. Yves Henry, in a recent work, has fully confirmed, in one sense, the essential points maintained by me, which had been so keenly contested; but before examining his conclusions, I should like to criticise some points on which I do not find myself in complete agreement with him.

M. Henry looks forward to the cultivation and export of bananas in the neighbourhood of the Mellakori and Pongo Rivers. As I have already said, I do not believe this to be possible, on account of the difficulties of irrigation and transpört.

Besides this, it would be difficult to find in this district the ground necessary for large plantations. The area of good soil not inundated during the winter in the low-lying district near the rivers, is very limited, and already occupied by the cultivations of the natives, which cannot be interfered with. Thus nearly the whole of the right bank of the Mellakori (a district I have some reason to know, having spent three years in visiting every corner of it), between Malighia and Kakutlai

\footnotetext{
1 It seems, however, that up to the hat, he firmly believed in the future of this phentation. A vinitor, three weoks before the proprietor's death, found it "in full beanty," though M. Vacher bad wed a cmaller quantity of manure then M. Teimonier.-Editorial Note, J. d'A. T.
} 
-marked on M. Henry's map as cultivable-is under water for several months in the year ; and the villagers cannot be deprived of the small amount of land available for their use.

The strip of land next the railway, then, seems to me the only one worth consideration. Unfortunately, the cultivable area is evidently very limited. I must admit however, that I am not well acquainted with the Kindia district, of which M. Henry speaks so enthusiastically; but some of my friends who have visited it do not share his hopes.

M. Henry's estimate for bringing the ground under cultivation seems to me far too low. He assumes an average cost of $250 \mathrm{fr}$. per hectare. Now, it will be necessary to dig up and utterly extirpate all stumps and roots, which, in Guinea, will bring up the cost to 1000 francs per hectare. This is a price which I have verified over and over again for myself, and all who have made experiments in agriculture in these countries, are agreed on this point.

In the same way, M. Henry overlooks, with regard to the European personnel, the cost of illness, and of the voyage home. In a general way we have to reckon that no agents or gardeners will pass more than twelve consecutive months in West Africa. To proceed on any other supposition would be to expose one's self to the risk of serious disappointments. I remember that, two years ago, when I maintained this opinion, my argument was met by the case of a Guiana plantation superintended by a retired naval lieutenant with the assistance of five gardeners, at a very low inclusive salary. Shortly afterwards it was announced that the lieutenant and four of the gardeners were dead.

As regards my own experiment, the scientific farmer who assisted me at first was compelled, by failure of health, to resign at the end of three months; and $M$. Don, the gardener who succeeded him, died on his return to France, after a stay of only ten months in Africa. I have no wish to generalise, and, personally, I have hitherto borne the tropical climate exceedingly well; but even so, from this point of view alone, one would be still better off in the Canaries.

On the other hand, I do not think that it is necessary to spend such a large sum on dwellings as that indicated by 
M. Henry. The most agreeable habitations in Guinea are huts built in the native manner, with clay walls and a thatched roof. For 5000 francs, one can build a very comfortable bungalow, raised a metre above the level of the soil, consisting of three large rooms, with ceilings and cement floors, and surrounded by a verandah $2 \mathrm{~m}$. 50 in width. Round native huts, of $5 \mathrm{~m}$. diameter and $4 \mathrm{~m}$. wall-height, cost no more than from 300 to $400 \mathrm{fr}$. to build, and are quite convenient to live in.

M. Henry's declaration as to the necessity for using strong doses of fertilisers is, in my opinion, the most important point in his study. I have mentioned the opposition aroused by my statements and those of M. Teissonnier. M. Henry admits that they are well founded, more particularly when he says that it is absolutely necessary to use manure composed of organic matter along with chemical fertilisers. The total amount of manure which he thinks will be needed in a year is smaller than that indicated by $M$. Teissonnier, but the arguments which he adduces to support his estimate have not yet been verified by experience. The money value attributed by him to farm-manure ( 180 francs for 30 tons, which is the quantity to be used per hectare) seems to me entirely fictitious.

M. Henry admits that the indispensable organic matter must be obtained either in the form of farm-manure or in that of compost and green manure; and he is of opinion-in which I am compelled to differ from him toto colo-that it will be quite easy to procure these fertilisers.

I have mentioned the difficulty of procuring and using animal manure in W. Africa. Its place might to a certain extent be supplied by green manures, but the problem of cultivating suitable plants at a profit in Guinea, still awaits solution. In the actual state of things it seems doubtful whether the value added to the crops by the application of this kind of fertiliser can compensate for the expense of grorving the leguminous plants necessary to furnish it. The use of composts might be easier, but it may be doubted whether they would by themselves be sufficient to answer the purpose of manure. In any case the experiment, a some- 
what complicated one, has not yet been made in West Africa.

The truth is that banana-growing in French Guinea is, as we have said, still in the experimental stage, and that several years of methodical work by means of enterprises conceived in a purely commercial spirit will be required before we can form any exact notion of its possibilities.

\section{E. Barllaud.}

[An editorial note appended to this article on its original appearance in the Journal d'Agriculture Tropicale, announced that it was to be followed up by a second, dealing with the special conditions which prevail in the semi-equatorial zone of West Africa, owing to the poverty of the soil and the length of the dry season, and more especially with the prospects of cotton-growing in the future. This article however, has not, so far as we can learn, yet appeared in print.] 